\title{
Title
}

\section{Law enforcement crowdsourcing initiatives: a Systematic Literature Review to identify key design elements.}

\begin{abstract}
Collective Intelligence on the Internet, managed through crowdsourcing, has allowed Internet users to put their eyes, ears, and minds at the service of professional security forces. The general objective is to support the security actions that these agencies carry out to ensure a safer society. Given the relevance of this topic, this paper studies through a systematic literature review how Collective Intelligence is being used as a support tool for the formal social control exercised by both states' security forces and professional corporations. Using a morphological approach, the paper also structures the eight basic general crowdsourcing elements (crowd, crowdsourcer, task, technology, crowd reward, crowdsourcer reward, participatory process, and open call) into a conceptual framework to present an integrated overview of the design options of the formal social control crowdsourcing initiatives studied. This analysis also allows to identify different relevant interdependencies between design elements.
\end{abstract}

\section{Keywords}

crowdsourcing, law enforcement, citizens, collective intelligence, social control, morphological framework

\section{Introduction}

The use of Information and Communication Technology (ICT) has inevitably had a huge impact on people's lives as, when the technology upon which a society is founded becomes modified, its routines and procedures are also, necessarily, altered. While this process has, to some extent, contributed to human welfare, it has also brought to light many unexpected dangers (Rescher, 1999). In this sense, the advancement of ICT has enhanced criminal activities in a range of previously unforeseen ways. For example, illegal behaviour mediated by network technologies has given rise to cybercrime. Theft, fraud, and harassment, amongst other felonies, have adopted new forms in cyberspace; and modern crimes, such as hacking, have come of age in our current, technological era. Such activities can be carried out in a 
more furtive way, owing to the anonymity and physical distance that ICT provides (Domdouzis et al., 2016).

In addition to cybercrime, new technologies have also fostered the informational and operational capacities of many illegal organizations. For example, Twitter was used in the British riots of 2011 as a key tool to coordinate anti-social behavior (Tonkin et al., 2012), and Telegram, the freeware, cloud-based, and high level encryption messaging service has been used by terrorists to promote their ideas and indoctrinate possible future recruits (Yayla and Speckhard, 2017).

However, at the same time, advancements in ICT have also enhanced the ways that law enforcement agencies can monitor and respond to criminal activities, both in cyberspace and in the physical environment. For example, through social media surveillance, potential criminal activity can be not only detected but also actively prevented (Domdouzis et al., 2016).

The problem here is that both the police and other security bodies have structural and cultural limitations that lead to a safety deficit because of the dispersed nature of the Internet (Huey et al., 2013). For example, it can happen that civil protection agencies do not make the most of the content that exists on social media, and, in doing so, they have an overdependence on more traditional technologies (Avvenuti et al., 2018).

This paper argues that security forces can make improvements by using Collective Intelligence (CI) through collaborative efforts with various public and private actors (Huey et al., 2013). This is not a completely new proposition. After all, initiatives like the Neighborhood Watch Program, which was created by the National Sheriffs' Association in 1972, sought to engage citizens in the fight against crime and to help communities bond together. In the modern world, however, Internet mediation provides the next step to bring such approaches in line with the technological age.

Through a CI initiative that is managed by processes like crowdsourcing, participants can be asked to carry out tasks that cannot be automatized in real time (Author2). As stated by Chang and Leung (2015), public-professional cooperation in criminal investigations is a growing phenomenon.

As has already been demonstrated by different studies, properly designed CI initiatives can generate better public services at lower costs (including those related to security issues), produce policy innovations that empower and engage citizens, and enhance government legitimacy (Liu, 2017). As a result, the profile of the citizen has changed from being just a consumer of public security services to being, in addition, an active agent taking limited actions to configure and manage those services. 
To be able to design initiatives of this type that can produce useful results improving citizens live, it is necessary to go deeper into the characteristics and configuration of such initiatives. Because of this, this study presents a systematic literature review (SLR) of the issue, focused in answering one question: which are the distinctive design elements that differentiate these security forces initiatives using crowdsourcing from other crowdsourcing initiatives. Using the information gathered answering this question, a morphological framework will be designed. This framework, with the results of the SLR, will allow to highlight some important interdependencies between design elements.

In the first part of the paper, these initiatives will be analysed within the field of criminology, whilst CI will also be related to the concept of crowdsourcing. After explaining the methodology that has been used, the different crowdsourcing projects found will be described through Author2 crowdsourcing framework. The next step will be the design of the morphological framework for formal social control crowdsourcing initiatives. After the discussion of the results, the article will draw some general conclusions about the use of CI in security initiatives and will give a proposal for new lines of research.

\section{Theoretical Background}

To fully understand how these initiatives work, is important to understand what collective intelligence is, and how can it be managed using crowdsourcing. It's also important to fit these types of initiatives inside the criminological field, what we achieve relating these CI initiatives with the formal social control.

\section{CI and crowdsourcing}

Malone (2018) defines CI as "the result of groups of individuals acting together in ways that seem intelligent". From this definition, three aspects need to be further clarified. Firstly, those "individuals" do not need to be people. They can be organizations, companies, or public institutions, as is the case with the examples discussed in this paper. Secondly, "acting together" refers to a connection between different "individuals" that can be the result of their direct cooperation, or by means of their competition. It can also result from a collation of individual contributions. Lastly, as those actions "seem intelligent", there is an important subjective dimension at work in CI which impacts upon the goals that any given agency is trying to achieve. 
CI can be used to solve problems in many different fields (Malone and Bernstein, 2015), such as marketing, finance, and research, amongst others. This is because it is a cross-sectional phenomenon and one that is inherent to many types of human activity.

When using these crowd involving initiatives, different ways to manage their action are available. One of them is crowdsourcing. Crowdsourcing arises when a suggestion for taking a task is given to a heterogeneous group in exchange for a reward. This task is proposed by the so-called "crowdsourcer", which can be an individual, a company, or even a governmental agency. The task entails the conscious and voluntary action of the crowd members and can involve finding a solution to a problem or contributing information to a collective end goal. A key determining factor for these initiatives to succeed is that they must have a mutual benefit for both the crowdsourcer and the crowd (Author2).

As for the infrastructure supporting these types of processes, ICT is fundamental. It allows thousands of people to interconnect whilst also permitting individuals to make specific contributions that are managed through technology (Malone, 2018).

\section{Crowdsourcing and the public}

One of the areas where crowdsourcing is being increasingly used is in the public domain. In this field, the crowdsourcer is, most often, a public agency and the crowd is mainly composed of private citizens, although it can also be constituted by NGOs, companies, and neighborhood associations.

Nam (2012) groups the type of tasks the crowd can perform into four categories: 1) the generation of information; 2) service coproduction; 3) solution creation; and 4) policy making. To know under what situations crowdsourcing can be used successfully in the public domain, the decision maker also must be aware of three further crucial elements: 1) what type of problem needs to be solved; 2) how crowdsourcing can help to achieve this; and 3) what crowdsourcing approach would be the most suitable (Brabham, 2013).

Each type of crowdsourcing task has a specific goal but the objective is always to empower citizens or organizations so that they are provided with valuable information for better decision making (Chandrasekaran et al., 2016).

In terms of the type of tasks that governments or their various departments ask the crowd to undertake, it is common to find many related to public security. This type of crowdsourcing action is 
particularly important because the prevention of any type of crime is crucial to the maintenance of social stability and the intellectual and financial growth of societies (Domdouzis et al., 2016).

\section{Crowdsourcing in crime prevention}

\section{Formal and informal social control by means of crowdsourcing}

From a criminology standpoint, the theory of daily or routine activities by Cohen and Felson (1979) allows crowdsourcing to be integrated into the public safety arena. According to this theory, crime arises from the confluence of three factors: an offender, a victim or object that motivates the offense, and social control (Redondo and Garrido, 2013). This latter aspect can be either formal or informal.

Informal social control is implemented by any non-professional organization or person that acts against crime without it being their specific professional activity. Because these parties lack the legal authority to act, their modus operandi focus on dissuasion and prevention (Redondo and Garrido, 2013). To apply these types of control by means of Internet crowdsourcing, citizens, as well as associations, NGOs and other non-governmental entities, promote initiatives that safeguard neighbourhoods and towns against a range of crimes (Author1). These initiatives sometimes focus on the reporting of specific behaviors, like "Chega de fiu fiu" which deals with sexual harassment (Brito et al., 2014), while other examples have a broader approach. The social network 'NextDoor', for example, allows all the neighbours in a specific district to communicate with each other about cohabitation problems, or incidents of burglary (Kelly, 2014).

In contrast, formal social control is carried out by professional agencies and its employees, such as the police force or security companies, whom they have entrusted monitoring, safety or control as professional activities. Although these bodies can carry out these tasks by theirselves, they often rely upon the cooperation of private citizens to, for example, report crimes or identify potential criminal suspects.

The relationship between formal social control and crowdsourcing is the focus of this paper, particularly in terms of public agency crowdsourcers that promote and manage crowdsourcing initiatives with the assistance of crowdworkers who are private citizens.

Formal and informal social controls differ in certain aspects, such as the legal capacity to act and the infrastructure that is available to use. However, an underlying relationship exists between them since 
both forms of control usually require the assistance of the wider community (Redondo and Garrido, 2013). This inter-dependence between control and community can also occur on the Internet, although it displays some importantly different characteristics.

Regarding this inter-dependence, security agencies sometimes use the information that has been generated by informal social control initiatives. Yet, despite this potentially vast pool of valuable information, there is a need for caution (Huey et al., 2013). After all, because the generation of information does not depend on the police (or any corresponding entity), they cannot always control the diffusion of, sometimes, rampant and potentially dangerous speculation. A clear example of this scenario can be seen with the Boston Marathon Bombings, where the perpetrators were misidentified by users of the 4Chan forum (Nahn et al., 2017).

\section{The relevance of crowdsourcing to public safety}

Thanks to the hyperconnectivity that is an inherent characteristic of today's ICTs, governments and other public organisms can easily connect with citizens both individually and in a group. More specifically, these connections can be realized through 'Communities of Interest' or 'Communities of Place'.

'Communities of Interest' are characterized by forming an alliance between people who share a common interest but who are not experts or professional practitioners in a particular field. In contrast, 'Communities of Place' gather people together who live in the same geographical area, such as an apartment block, a neighborhood, or a city, etc. Obviously, the connection between these communities and their local governments is founded upon the promotion of public safety.

In these cases, the communities - whether of Interest or Place- act as crowdworkers carrying out different tasks to support public safety professionals. These tasks can range from reporting crimes or analyzing multimedia content to taking part in so-called "wikified" investigations (Chang and Leung, 2015; Author1).

\section{Methodology}

\section{Systematic Literature Review}

In this paper, a systematic literature review (SLR) has been carried out following the recommendations of Denyer and Tranfield (2013) and Xiao and Watson (2019). Next, the different parameters used in the 
review protocol are described.

Research question. This SLR tries to answer one question: which is the expression of its design elements that differentiate these security forces initiatives using crowdsourcing from other crowdsourcing initiatives. This question is relevant for those public security agencies planning to use crowdsourcing safety-related initiatives, helping in its design and deployment.

Inclusion criterion. The selected documents were those that name or describe crowdsourcing initiatives related to security issues in which the crowdsourcer is an official security organization or a public department. Only documents in Spanish or English were included.

Literature identification. The literature search was done using the databases and search strings of Table 1 . The title of the selected documents was analysed selecting only those referring to security issues. The selected documents were saved automatically using Zotero software, which automatically saves title, abstract and other relevant metadata. Because the term crowdsourcing was coined in 2006, the search was limited to documents with a publication date from 2006 to 2020. In the first search, 309 documents were identified, number reduced to 268 after discarding repeated results (41). Due the novelty of the issue, and according to Denyer and Tranfield (2013) when they explain the importance of gray literature, two news sources have been consulted: BBC News and CNN News. In both sources, news about crowdsourcing were searched, selecting only those relevant for the SLR. In the BBC case, 352 publications were found and 4 were finally selected. In the CNN case, 164 publications were found and 6 were finally selected.

Table 1. Databases consulted and the search string used in each case

\begin{tabular}{|l|l|l|}
\hline Database & Search String & Outcomes \\
\hline IEEExplore & $\begin{array}{l}(((\text { Document Title":crowdsourc*) OR "Document Title":crowd- } \\
\text { sourc*) AND law enforcement) }\end{array}$ & 24 \\
\hline Springer & $\begin{array}{l}\text { 'crowdsourc* | crowd-sourc* \& ("law enforcement" | crime | } \\
\text { criminal*)' }\end{array}$ & 48 \\
\hline WOS & $\begin{array}{l}\text { TI=(crowdsourc* OR crowd-sourc*) AND TS=("law enforcement" } \\
\text { OR crime OR crimin*) }\end{array}$ & 21 \\
\hline SCOPUS & $\begin{array}{l}\text { TITLE(crowdsourc* OR crowd-sourc*) AND ALL("law } \\
\text { enforcement" or "crime" or criminal*) AND PUBYEAR AFT 2006 }\end{array}$ & 116 \\
\hline Google Scholar & crowdsourcing crime OR criminal OR "law enforcement" & 100 \\
\hline & TOTAL ARTICLES & 309 \\
\hline
\end{tabular}


Screening for inclusion. The abstract of the found documents was read to further decide their relevance to the research topic. Many documents were discarded because were about crowdsourcing initiatives driven by public organisms, but that were not security-related. After this, 66 documents were considered relevant for the research, and the full-text paper was obtained for quality assessment.

Quality and eligibility assessment. Because the purpose of the SLR is to obtain documented examples of security-related crowdsourcing initiatives, the quality of the documents is not particularly relevant. As it will be indicated later in the paper, each initiative found is subjected to an extra analysis obtaining information from other sources, growing and checking the collected information. Because the characteristics that define a crowdsourcing initiative can be understood as a continuum (Sloan, 2012), a wider conception of the term has been used when identifying initiatives.

Iterations and full-text analysis. After reading the selected documents, 19 more were added through backward search, increasing its number to 75. After analyzing the different initiatives described in these papers, 48 papers were discarded because the crowdsourcer of the initiatives was not a public agency. The final set of selected documents was 27 .

Data extraction. The main elements of the crowdsourcing initiatives that appear in these documents were extracted following the Author 2 crowdsourcing framework design elements. This framework describes eight elements that make up any crowdsourcing initiative: the crowd, the crowdsourcer, the task to be done, the technology used, the crowd reward (if any), the crowdsourcer reward, the participatory process that the task implies, and the open call to reach the crowd. Any particularity of these elements is also gathered and registered, as can be seen in Table 2. This information was garnered from the papers themselves, the websites on which the initiatives was published and, when these websites were not available, by using archive.org.

Descriptive results. All the data gathered about formal social control crowdsourcing initiatives is presented using again the Author2 framework. Any information, or particularity, about any of the design elements is mentioned and described. For example, about the task (one of the framework elements), different information is gathered: the type of task, the time to take it or the geographical scope, for example. 
Table 2. List of initiatives, projects, or events using crowdsourcing in formal social control

\begin{tabular}{|c|c|c|c|c|c|c|}
\hline Reference & Initiative name & Organization type & $\begin{array}{c}\text { Geographical } \\
\text { scope }\end{array}$ & Organization name & Time scope & Task Name \\
\hline Zeteky, n.d. & Torch & $\begin{array}{c}\text { Enterprise } \\
\end{array}$ & Local & Enterprise for LWA & Permanent & Crime reporting \\
\hline Livingstone, 2013 & $\begin{array}{l}\text { LERN (Liberia's Early-Warning } \\
\text { and Response Network) }\end{array}$ & $\begin{array}{l}\text { Government + NGOs + UN + civil } \\
\text { organizations }\end{array}$ & National & $\begin{array}{l}18 \text { civil society organizations, government } \\
\text { agencies, UN agencies, and NGOs }\end{array}$ & $\begin{array}{l}\text { Permanent } \\
\text { (closed) }\end{array}$ & Incident and crime reporting \\
\hline $\begin{array}{l}\text { Chand, Sankaranarayanan, } \\
\& \text { Sharma, } 2014\end{array}$ & Project Jagriti & National government + private entity & National & $\begin{array}{l}\text { Child Wellfare commite (Government } \\
\text { department) and private entity }\end{array}$ & Permanent & Crime reporting \\
\hline Shiffman, 2013 & $\begin{array}{c}\text { Neighborhood Network Watch } \\
\text { programme }\end{array}$ & National government & National & U.S. Department of Homeland Security & Permanent & $\begin{array}{l}\text { Information gathering and } \\
\text { crime reporting }\end{array}$ \\
\hline Andrews et al. 2017 & ATHENA & $\begin{array}{c}\text { Government + Law Enforcement } \\
\text { Agencies + Academia + Private sector }\end{array}$ & Local & West YorkShire Police and others & Punctual & Information gathering \\
\hline Matveeva, 2013 & $\begin{array}{l}\text { Local government elections in } \\
2012\end{array}$ & International NGO & Local & United Nations Development Programme & Punctual & Specific crime reporting \\
\hline Matveeva, 2013 & REACH & International NGO & Local & $\begin{array}{l}\text { ACTED (Agency for Technical Cooperation } \\
\text { and Development) }\end{array}$ & Permanent & Information gathering \\
\hline Matveeva, 2013 & $\begin{array}{l}\text { Local government elections in } \\
2011\end{array}$ & International and local NGO & Local & $\begin{array}{l}\text { United Nations Development Programme and } \\
\text { network of NGOs }\end{array}$ & Punctual & Specific crime reporting \\
\hline Markowsky, 2013 & $\begin{array}{l}\text { Boston Martathon Bombing event } \\
\text { (1) }\end{array}$ & Law enforcement & Local & 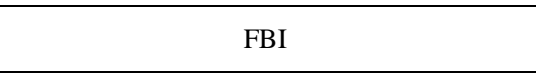 & Punctual & Multimedia reporting \\
\hline $\begin{array}{l}\text { Ariffin, Hanif, \& Solemon, } \\
2015\end{array}$ & MyDistress & Law enforcement & National & Royal Malaysian Police Department & Permanent & Crime reporting \\
\hline $\mathrm{BBC}, 2017$ & Eu Most Wanted & Law enforcement & International & Europol & Permanent & Criminal identification \\
\hline BBC, 2017 & Stop Child Abuse & Law enforcement & International & Europol & Permanent & Information gathering \\
\hline Chandrasekaran et al, 2016 & $\begin{array}{l}\text { Winter Storm Nemo (2013) and } \\
\text { Hurrican Sandy (2012) events }\end{array}$ & Law enforcement & Local & NY Police Department & Punctual & Information gathering \\
\hline Denef et al., 2013 & \#shopalooter & Law enforcement & Local & Greater Machester Police (GMP) & Punctual & $\begin{array}{l}\text { Information gathering and } \\
\text { specific crime reporting }\end{array}$ \\
\hline Denef et al., 2013 & UK Riots event & Law enforcement & Local & $\begin{array}{c}\text { London Metropolitan Police (MET) and the } \\
\text { Greater Manchester Police (GMP) }\end{array}$ & Punctual & $\begin{array}{l}\text { Information gathering and } \\
\text { specific crime reporting }\end{array}$ \\
\hline Denef et al., 2013 & FaceWatch ID & Law enforcement & Local & Northamptonshire Police & Punctual & $\begin{array}{l}\text { Information gathering and } \\
\text { specific crime reporting }\end{array}$ \\
\hline FBI, 2014 & ISIL tips & Law enforcement & National & FBI & Punctual & Criminal identification \\
\hline Khanwalkar, 2015 & FBI Tips And Public Leads & Law enforcement & National & FBI & Permanent & $\begin{array}{l}\text { Information gathering and } \\
\text { crime reporting }\end{array}$ \\
\hline Khanwalkar, 2016 & iWatchLA & Law enforcement & Local & Los Angeles Police Department & $\begin{array}{c}\text { Permanent } \\
\text { (closed) }\end{array}$ & Suspicious activity reporting \\
\hline Lally, 2016 & Texas Virtual Border Watch & Law enforcement & Local & County Sheriffs & Permanent & Specific crime reporting \\
\hline Lally, 2016 & $\begin{array}{l}\text { Philadelphia Police use of Social } \\
\text { networks }\end{array}$ & Law enforcement & Local & Philadelphia Police Department & Punctual & Criminal identification \\
\hline Markowsky, 2013 & $\begin{array}{l}\text { Boston Martathon Bombing event } \\
\text { (2) }\end{array}$ & Law enforcement & Local & FBI & Punctual & Criminal identification \\
\hline Markowsky, 2013 & The brooklyn Mugging event & Law enforcement & Local & New York Police Department & Punctual & Criminal identification \\
\hline
\end{tabular}




\begin{tabular}{|c|c|c|c|c|c|c|}
\hline McHugh, 2011 & TipSubmit & Law Enforcement & Local & Chicago Police Department & Permanent & Crime reporting \\
\hline Ministry of Interior, n.d. & AlertCops & Law enforcement & National & National police and Guardia Civil & Permanent & $\begin{array}{l}\text { Information gathering and } \\
\text { crime reporting }\end{array}$ \\
\hline Nahn et al., 2017 & 2011 Vancouver Riots events & Law enforcement & Local & Vancouver Police Department & Punctual & Criminal identification \\
\hline Perlman \& Pulidindi, 2012 & E-policing & Law enforcement & Local & Los Angeles Police Department & Permanent & Crime reporting \\
\hline Yang, 2016 & $\begin{array}{l}\text { "i-Witness", inside Police@ @G } \\
\text { App } \\
\end{array}$ & Law enforcement & National & Singapore Police Force & Permanent & Crime reporting \\
\hline Hamilton et al., 2011 & MyPD App & Law enforcement & Local & Palm Beach (Florida) Police Department & Permanent & Crime reporting \\
\hline Hamilton et al., 2011 & See something, say something & Law enforcement agencies & Local & $\begin{array}{c}\text { Safer Travel Partnership (Transport for West } \\
\text { Midlands, part of the West Midlands Combined } \\
\text { Authority, West Midlands Police, British Transport } \\
\text { Police and transport operators) } \\
\end{array}$ & $\begin{array}{l}\text { Permanent } \\
\text { (closed) }\end{array}$ & $\begin{array}{l}\text { Low-level anti-social } \\
\text { behaviour reporting }\end{array}$ \\
\hline Shiffman, 2013 & Estonia DDoS event & $\begin{array}{l}\text { Law Enforcement agencies, Government, } \\
\text { TI Enterprises, etc. }\end{array}$ & National & Estonia government and others & Punctual & $\begin{array}{c}\text { Cyber-operations (block IP- } \\
\text { Addresses) }\end{array}$ \\
\hline Brito et al., 2014 & Map Contra el Crimen & Law enforcement and other orgs. & Local & $\begin{array}{l}\text { Honduran National Police and other non } \\
\text { governmental orgs. }\end{array}$ & $\begin{array}{c}\text { Permanent } \\
\text { (closed) }\end{array}$ & Crime reporting \\
\hline Hamilton et al., 2011 & NYC 311 & Local government & Local & City of New York & Permanent & $\begin{array}{l}\text { Incident, suspicious behaviour } \\
\text { and crime reporting }\end{array}$ \\
\hline Shah et al., 2011 & BOSS:311 & Local government & Local & City of Boston & Permanent & Report non-emergency issues \\
\hline Macini, 2013 & Disque Denúncia & Local government + Private $+\mathrm{NGO}$ & Local & $\begin{array}{c}\text { Rio de Janeiro local police, NGO and private } \\
\text { organizations }\end{array}$ & Permanent & Crime reporting \\
\hline Musila, 2013 & $\begin{array}{l}\text { CEWARN (Conflict Early } \\
\text { Warning and Response } \\
\text { Mechanism) }\end{array}$ & National governments collaboration & International & $\begin{array}{l}\text { Intergovernmental authority on Development } \\
\text { (IGAD): Eritrea, Kenya, Ethiopia, Somalia... }\end{array}$ & Permanent & $\begin{array}{l}\text { Information gathering and } \\
\text { crime reporting }\end{array}$ \\
\hline Musila, 2013 & ICT4Peace & National governments collaboration & International & $\begin{array}{l}\text { Intergovernmental authority on Development } \\
\text { (IGAD): Eritrea, Kenya, Ethiopia, Somalia... }\end{array}$ & Permanent & $\begin{array}{l}\text { Information gathering and } \\
\text { crime reporting }\end{array}$ \\
\hline Puig Larrauri, 2013 & $\begin{array}{l}\text { CEWERS (Conflict Early Warning } \\
\text { and Early Response System for } \\
\text { South Sudan) }\end{array}$ & National governments collaboration & International & $\begin{array}{l}\text { Intergovernmental authority on Development } \\
\text { (IGAD): Eritrea, Kenya, Ethiopia, Somalia... }\end{array}$ & Permanent & $\begin{array}{l}\text { Information gathering and } \\
\text { crime reporting }\end{array}$ \\
\hline Castillo, 2020 & $\begin{array}{c}\text { Alertadores Internos y Externos de } \\
\text { la Corrupción }\end{array}$ & National government & National & Secretaría de la Función Pública (México) & Permanent & Specific crime reporting \\
\hline DipNote, 2015 & DipNote Blog & National government & National & Department of State (U.S.A.) & Punctual & Brainstorming \\
\hline Dunphy, 2015 & The Shoreditch Digital Bridge & National government & Local & UK Government & $\begin{array}{c}\text { Permanent } \\
\text { (closed) }\end{array}$ & Criminal identification \\
\hline El Abdallaoui et al., 2016 & TrackChild & National government & National & $\begin{array}{l}\text { Indian Ministry of Women and Child } \\
\text { Development }\end{array}$ & Permanent & $\begin{array}{l}\text { Missing child reporting and } \\
\text { identification }\end{array}$ \\
\hline Khanwalkar, 2015 & Internet Signalement & National government & National & Ministère de l'Intérieur (France) & Permanent & Crime reporting \\
\hline Khanwalkar, 2016 & See something, say something & National government & National & US Department of Homeland Security (DHS) & Permanent & $\begin{array}{l}\text { Incident, suspicious behaviour } \\
\text { and crime reporting }\end{array}$ \\
\hline Puig Larrauri, 2013 & $\begin{array}{l}\text { CRMA (Crisis and Recovery } \\
\text { Mapping and Analysis Project) }\end{array}$ & National government and citizens & National & $\begin{array}{c}\begin{array}{c}\text { Sudan State Government and communities of } \\
\text { citizens }\end{array} \\
\end{array}$ & Permanent & $\begin{array}{l}\text { Incident, suspicious behaviour } \\
\text { and crime reporting }\end{array}$ \\
\hline Matveeva, 2013 & $\begin{array}{l}\text { Early warning system in southern } \\
\text { Kyrgyzstan }\end{array}$ & International NGOs collaboration & Local & $\begin{array}{c}\text { Organization for Security and Co-operation in } \\
\text { Europe (OSCE), United Nations Development } \\
\text { Programme (UNDP), and Foundation for } \\
\text { Tolerance International (FTI). } \\
\end{array}$ & Permanent & $\begin{array}{l}\text { Information gathering and } \\
\text { crime reporting }\end{array}$ \\
\hline
\end{tabular}




\section{Morphological framework design}

The description of the different design elements is consolidated using a morphological framework. This framework allows to present a cohesive, integrative and general overview of the formal social control crowdsourcing initiatives. This analysis is done following the example of Karachiwalla and Pinkow (2021). These authors, following Richey (2013) recommendations about morphological framework design, use this methodology to describe and analyse the design elements in contest crowdsourcing initiatives.

To develop any morphological framework the following steps are taken:

1. Important dimensions are identified.

2. Those dimensions are broken down into subdimensions.

3. For each dimension and/or subdimension, possible values or attributes are identified.

4. The data extracted in previous steps is integrated and structured into a matrix: the morphological box

This morphological box allows to see all the possible design elements combinations, and decide different possible configurations instead of following a single solution (Karachiwalla and Pinkow, 2021). This means that also the different relationships between elements can also be identified and investigated.

About the SFC crowdsourcing initiatives, this framework is important for practitioners when facing the initiative design phase.

\section{Results}

\section{Analyzed Cases}

After the analysis of the selected documents, 46 initiatives from official agencies that used crowdsourcing were identified and documented. Table 2 displays them all, including some of the characteristics collected.

\section{Design elements}

In the following section a summary of the design elements that comprise the crowdsourcing initiatives listed in Table 2 is shown using a concept-centric approach. In each element, a first description of the 
results, based on the SLR findings, is done. Then, any particular feature of that element found in the literature is described and analysed.

\section{Element 1. The crowdsourcer}

In the analyzed cases four different types of crowdsourcers have been identified:

- Law enforcement agencies. This is the biggest group (53\% of the total) and includes local police bodies from different cities as well as organisms with a broader infrastructure, such as the FBI (Markowsky, 2013) or Europol (BBC, 2017)

- Governments. These account for $31 \%$ of the overall examples studied. Sometimes, they relate to local councils, while, at other times, they are departments within national governments.

- International organizations. Although there are fewer cases of these in the sample (4\%), organizations such as the United Nations have the infrastructure and resources required to launch this type of initiatives.

- Hybrid. Eleven per cent of the remaining cases correspond to initiatives launched by various organisms. Sometimes, they are governments from neighbouring countries that face a common problem (Larrauri, 2013). In other cases, cooperative action is taken by governments or law enforcement agencies with the support of other organisms, such as NGOs, IT enterprises, and universities, etc. (Shiffman, 2013)

From the above, the most prominent crowdsourcing type is the one related to law enforcement agencies which, either on their own or in collaboration with others (through the hybrid model) account for $65 \%$ of the total. Being local, it is easier to encounter Communities of Interest and Communities of Place that are more willing to participate in the initiatives.

\section{Credibility}

The crowdsourcer credibility is a key element in the crowdsourcer and crowd relationship. A lack of confidence on the part of the latter will negatively affect vertical government-to-citizen ICT interventions (Mancini, 2013). For example, as Muggah and Diniz (2013) indicate, in socioeconomically deprived areas in Brazil, Colombia and Mexico, citizens are wary of using ICTS to report illegal activities for fear of being tracked down and punished. 
This lack of credibility can be caused by different factors, such as the abuse of power, a longstanding legacy of repressive policing and state violence, or corrupt governments, amongst others (Mancini, 2013; Musila, 2013).

\section{Loss of control}

As the use of crowdsourcing requires participants' involvement to solve a problem, it is necessary to cede the crowdsourcer's control, to a certain extent. This impacts on the development of the initiative (Hui, 2015).

However, this loss is, in some cases, unacceptable. This situation can occur, for example, in the case of those problems where crowdsourcing and CI are not the most adequate tools, such as when the solution to an initiative requires the use of confidential information that cannot be made public.

In contrast, when the crowdsourcer's loss of control is acceptable, Denef et al. (2013) suggest two different approaches. In the "instrumental" approach, the crowdsourcer retains more control over the initiative, which grants only limited participation to citizens. In contrast, the "expressive" approach generates a closer relationship between crowdsourcers and citizens but it makes the management of the project more difficult.

\section{Element 2. The crowd}

From the collated examples, four different types of crowd can be identified.

- Citizens. This is the most common type of crowd as it accounts for $64 \%$ of the total. These participants are required when the problem to be solved presents geographical specificities, such as, with crimes that are committed in a particular district, city, or nation.

- Internauts. Internet users (as a global category) account for $4 \%$ of the total. In contrast to citizens, they are required for situations that have no specific geographical locations, such as in the case of "Stop Child Abuse" (BBC, 2017), or when the crime or problem to be solved occurs in cyberspace (Khanwalkar, 2016).

- Hybrid. This type of crowd is the second most common as it accounts for $16 \%$ of the total. It involves instances where the crowd is made up of a various groups of crowdworkers, from citizens and Internet users, as in "Texas Virtual Border Watch" (Laly, 2016), to companies, universities and other governmental departments (Shiffman, 2013). 
- NGOs. Although these account for only $7 \%$ of the total, occasionally, when it comes to sensitive data issues, more professionally organized structures are required. For example, the UNDP resorted to NGOs to alert them to irregularities in electoral processes (Matveeva, 2013).

It is important to note that the classification of the crowd given above is not exclusive. Thus, for any specific initiative, one can participate as a citizen and as an internaut at the same time.

Sometimes, the different participants get grouped in the so-called "civilian police": people who undertake online collective action through pooling resources (such as time and participants' commitment to the cause) to investigate online crimes and report their findings to law enforcement agencies (Huey et al., 2013). However, both citizen crowds or civilian police groups have the same goal: to meet desired collective online security outcomes by mobilizing their resources and providing evidence of online criminal activity to law enforcement agencies and/or private entities (Huey et al., 2013).

\section{Motivation}

There are two types of motivation: intrinsic and extrinsic. Intrinsic motivation is vital for CI initiatives as it is an effective way to achieve and maintain participation. However, it is also more difficult to generate because it is, very often, beyond the crowdsourcer's control. Some examples of intrinsic motivation are those occasions when participants feel that they are part of a good cause, or that they are contributing to the greater good of society (Huey et al., 2013). In addition, the desire to help others, to assist in the search for justice, the wish to protect others and prevent victimization, to assist law enforcement, and to help to maintain neighborhood safety, are other effective intrinsic motivations (See et al., 2016).

In contrast, extrinsic motivation refers to obtaining a tangible profit in exchange for participation. Some initiatives have been identified where that 'tangible' represents information about traffic problems, evidence of a response to the reporting of waste/environmental problems, different kinds of advice, and access to data, amongst others (See et al., 2016).

\section{Technological skills}

The importance of technological skills is obvious because crowdsourcing initiatives are taken through technology (not only Internet). In some cases, high or medium technological skills are enough. For example, when using Apps like 'AlertCorps' (Ministry of Interior, n.d.) or websites like 'BOS:311' (Shah et al., 2011). In other cases, simpler technology as SMS needs to be used, as described by Matveeva (2013). 


\section{Geographical location}

In many cases, the crowd geographical location characteristics limit the possibilities of implementing crowdsourcing initiatives due to technological incidents such as inadequate access or unstable wifi signals (Musila, 2013). This will be important when trying to reach a concrete community of place that lives in a tech-limited location.

\section{Cultural characteristics}

The culture of a region represents a structural challenge to crowdsourcers because factors such as beliefs or traditions can undermine a crowdsourcing initiative (Musila, 2013). Certain behaviors are more culturally acceptable in some countries, whereas, in others, they can be criminalized. For example, Chang and Leung (2015) describe different doxing practices in China that would be illegal or morally questionable in other countries.

\section{Element 3. The task}

Three general tasks can be identified from the sample through which the crowd serves as additional 'eyes and ears' for law enforcement (Nahn et al., 2017). These are:

- $\quad$ Crime reporting

- $\quad$ Suspect identification

- Information gathering

In the case of crime reporting, three distinct levels can also be distinguished depending on the severity of the activity that is being reported:

(1) Applications like 'Torch' (Zeteky, n.d.) or 'Disque Denúncia' (Muggah and Diniz, 2013) are used by state security forces to ask the crowd to report crimes such as robberies, assaults, etc.

(2) Other applications like 'NYC 311' (Hamilton et al., 2011) or 'Citizens Connect' (Shah et al., 2011) request reports only about low-level anti-social behavior, such as acts of graffiti or damage to public property.

(3) Some initiatives ask for reports about activities that, whilst not being illegal in themselves, could be related to crime or could be the cause of it. ' $W a t c h L A$ ' or 'See Something, Say Something' (Khanwalkar, 2016), for example, relate to these types of activities. Early warning is a special 
case as this focuses on conflict prevention activities through avoiding political violence (Macini, 2013).

There are also other, more uncommon tasks, which illustrate the high utility of these types of initiatives. One example is the cyberspace operation that was performed in the case of DDoS attacks on Estonia (Shiffman, 2013).

\section{Task specificity}

The three different tasks described before can have two different levels of specificity: concrete or general.

When asking the crowd to report a crime, there are initiatives that ask for the reporting of concrete felonies, like ‘Alertadores Internos y Externos de la Corrupción' (Castillo, 2020) which is used for corruption cases in Mexico. Others, like 'AlertCorps' (Ministry of Interior, n.d.) allows the user to report on many different types of crimes.

Regarding the identification of specific individuals, this task is mainly used for identifying missing children or adults, such as via 'TrackChild' (El Abdallaoui et al., 2016), or for identifying criminals who have escaped capture, as in the 'EU Most Wanted' campaign (BBC, 2017). In other cases, persons who meet certain criteria are asked for identification, like with the rioters in the Manchester riots (Denef et al., 2013).

Finally, the task of information gathering refers to the collation of a wide variety of data. For example, the initiative 'Stop Child Abuse', launched by Europol, asks the crowd to identify certain elements that appear in photographs (such as a specific brand of cereal, or the origin of a particular type of pyjamas) that are related to pedophile suspects. By doing so, they can obtain valuable clues about the geographical location in which the original picture was taken (BBC, 2017). In other initiatives, general data is asked for. For example, in the Boston Marathon bombings any type of multimedia material taken in the terrorist attack place was asked for (Nahn et al., 2017).

\section{Timing}

In relation to the sample of initiatives analysed in this paper, all the initiatives can be classified as punctual or permanent. Punctual initiatives are those that are launched to solve a specific problem and their timings are very restricted. This was the case with the collation of multimedia materials related to the Boston Marathon Bombing. After the attack, the FBI asked participants for any content (such as, 
photos or videos) that contained relevant information about the incident (Nahn et al., 2017). The main goal here was the identification of the terrorists. In the cases analyzed in this paper, this type of initiative represents $67 \%$ of the total.

On the other hand, there are those initiatives that are expected to operate in the long-term, often with the goal of trying to solve one or more general (rather than specific) problems. For example, 'Mapa contra el crimen' (Brito et al, 2014) allowed citizens to report crimes (of any type) that were then marked on a collaborative map. In the cases analyzed, $33 \%$ of the initiatives conform to this timing criterion.

Both types of initiatives can complement each other. As stated by Mancini and O’Reilly (2013), punctual initiatives can be used to forestall a crisis, while long-term initiatives can also address the root causes of the problem.

\section{Geographical area}

All the initiatives that have been studied in this paper try to tackle a problem that is geographically determined. There are three types of scope: local, national, or international.

The more restricted the geographical area, the easier it is to find a crowd (communities of place) that might be interested in participating in solving the problem or crime. In addition, the allocation of resources can be optimized through this type of initiative. However, the geographical scope of the CI will depend on the specificity of the crime that is being tackled.

Most of the cases $(56 \%)$ that have been analyzed here are local to specific cities or regions. In these cases, it is normally local security agencies that is operational, such as local police departments or local councils. This is the case, for example, with \#shopaloter initiative organized by Greater Manchester Police (GMP) (Denef et al., 2013), or 'NYC 311' in New York City (Hamilton et al., 2011).

However, $33 \%$ of the initiatives analyzed here try to solve problems at a national level. In these cases, it is national governmental organisms who takes the role of the crowdsourcer, such as, the FBI or US government with "ISIL tips" or the National Police in Spain with “AlertCorps" App.

Finally, the least common geographical area that is involved in the initiatives analyzed in this paper operate at an international level (only $11 \%$ of the total). In these cases, it is supranational bodies that act, such as the EU itself, the UN with its development agenda, or IGAD (Musila, 2013), which is an organism with which Eritrea, Kenya, Ethiopia, and other African countries participate.

\section{Quality of the information}


Here the term 'information' refers to both that which is given to the crowd, as well as that which the crowd generates. The quality and credibility of this information is particularly important because crowdsourcing initiatives can often deal with sensitive data (Musila, 2013; Dunphy, 2015)

On the one hand, the description of the task that is given to participants must be clear to avoid confusion. In addition, any materials that are provided (if there are any) to undertake the task must be of sufficient quality. These two characteristics are fundamental so that the crowdsourcer can obtain optimal results from the initiative.

Depending on the initiative, once information has been obtained from the crowd, it is important to carry out a review because the credibility of the data is not automatically guaranteed. This could include cross-referencing the information that has been obtained from various sources (Musila, 2013), including other CI initiatives (Muggah and Diniz, 2013). By doing this, trolls and other fake information sources can be identified and eliminated.

Many comparative studies have shown that certain crowdsourced information can be as good as the data collected from professional sources (See et al., 2016)

\section{Element 4. Technological infrastructure}

In most of the cases that have been analyzed, the Internet is the most popular medium to use for crowdsourcing, either by means of websites (which accounts for $53 \%$ of the total), applications (18\%), or both media $(13 \%)$.

\section{Type of technology used}

However, two different types can be distinguished:

(1) Crowdsourcing initiatives that are based on specific projects or applications, such as the apps 'AlertCorps' (Ministry of Interior, n.d.) or 'BOS:311', which also has a web version (Shah et al., 2011).

(2) Crowdsourcing initiatives that use the web or social networks that already exist (Nahn et al., 2017), such as '\#shopalooter' initiative or '2011 Vancouver Riots' event, that work on Twitter (Denef et al., 2013; Lally, 2016) 
On the other hand, there are initiatives (13\% of the total) that use not only the Internet but also other technologies. In some cases, this is due to the complexity and significance of the initiative, such as in 'CRMA' (Larrauri, 2013).

\section{Processing costs}

Another issue to consider is the cost of processing the information that has been collected. Social networks, for example, can be a perfect tool to obtain data from the crowd. However, because these platforms are not automatically suited to public participation in governance or public initiatives, the interactions that they generate cannot be guaranteed to produce reasonable and transparent information that can be easily processed (Knox, 2016). On the contrary, creating platforms or apps ad hoc for certain situations, although will allow fast and easy processing, will lack high level of participation.

\section{Element 5. Open call}

In crowdsourcing initiatives, participation can be given to anyone using an open call. This is the most predominant type of call in the cases that have been analyzed here as $78 \%$ of them invited public citizens and Internet-users to participate. One example of an open call is the 'EU Most Wanted' campaign where all European citizens were included. In contrast, specific groups can also be targeted, such as in 'NYC $311^{\prime}$ which was addressed mainly to the citizens in New York City.

In other cases, the open call can be restricted to specific types of crowd who meet a predetermined profile, such as is the case of NGOs (Matveeva, 2013).

\section{Elements 6 and 7. Crowdsourcer and crowdworkers reward}

To succeed, crowdsourcing initiatives must provide mutual benefits between the crowd and the crowdsourcer (Author2). For the crowdsourcer, the expected benefit is the appropriate accomplishment of the task. However, for the crowd, the nature of their reward can vary.

In all the analysed examples, the main reward is to achieve a safer environment (in a specific neighbourhood, city, etc.). This type of reward, or incentive, is an intangible one. Anyway, the crowdsourcer can offer other rewards, either intangible (like public recognition) or tangible (like money or merchandising). 


\section{Element 8. Participatory process}

According to Bigham et al. (2015) there are three different types of crowd participation: (1) directed crowdsourcing, where each individual carries out the task independently; (2) collaborative crowdsourcing, in which individuals cooperate whilst undertaking the task; and (3) passive crowdsourcing, which is based on obtaining information and data from the crowd's behavior.

In all the initiatives that have been analyzed here, directed crowdsourcing was involved in the reporting of crimes. Only in the specific case of the DDoS in Estonia (Shiffman, 2013) can collaborative crowdsourcing be identified. As for the last type of crowdsourcing, no evidence of this has been identified in the research data.

\section{A Morphological framework on crowdsourcing formal social control initiatives}

For the design of the morphological framework about SFC crowdsourcing initiatives:

1) Dimensions are obtained from Author 2 crowdsourcing framework, dimensions that are present in any crowdsourcing initiative.

2) These dimensions are broken down in elements, that are identified thanks to the descriptive section of the SLR.

3) The elements attributes or values are also identified through the descriptive section.

The resultant morphological box is represented in Table 3.

\section{Discussion}

The use of crowdsourcing within the public sphere is becoming increasingly important. Public institutions seeking to ingratiate themselves with their citizens are turning to crowdsourcing as a way to strengthen ties or increase trust with them. For that reason, this paper provides an overview of this type of citizen security-oriented initiative. By means of the morphological framework, the different elements that make up these initiatives are shown, which can help practitioners when designing them. Thanks to the SLR, a series of relationships between the different design elements that must be considered are also identified and whose compendium represents a further contribution of this paper at a practical level. 
Table 3. A morphological framework of FSC crowdsourcing initiatives

\begin{tabular}{|c|c|c|c|c|c|}
\hline Dimensions & Element & Specifications & & & \\
\hline \multirow[t]{3}{*}{ Crowdsourcer } & Type & Law enforcement & Governments & International Organizations & Hybrid \\
\hline & Credibility & High & Medium & Low & \\
\hline & Loss of control & Not allowed & Allowed - instrumental & Allowed - expressive & \\
\hline \multirow[t]{5}{*}{ Crowd } & Type & Citizens & Internatus & NGOs & Hybrid \\
\hline & Motivation & Intrinsic & Extrinsic & Both & \\
\hline & Previous knowledge & High & Medium & Low & \\
\hline & Tech skills & High & Medium & Low & \\
\hline & Cultural believes & Supports initiative goal & Unsupports initiative goal & & \\
\hline \multirow[t]{6}{*}{ Task } & Type & Crime reporting & Suspect identification & Information gathering & Others \\
\hline & Specificity & Concrete & General & & \\
\hline & Timing & Punctual & Permanent & & \\
\hline & Geographic area & Local & National & Internacional & \\
\hline & Quality information provided & High & Medium & Low & \\
\hline & Quality information produced & High & Medium & Low & \\
\hline \multirow[t]{3}{*}{ Technology } & Type & Web & App & Both & Others \\
\hline & Ownership & Custom-made own tech & $3^{\text {rd }}$ owned tech & & \\
\hline & Processing costs & High & Medium & Low & \\
\hline Open Call & Type & General & Specific - practitioners focused & Specific - location focused & \\
\hline \multirow[t]{2}{*}{ Crowd reward } & Type & Tangible & Untangible & & \\
\hline & Timing & Short term & Long term & & \\
\hline $\begin{array}{l}\text { Participatory } \\
\text { process }\end{array}$ & Type & Directed & Collaborative & Passive & \\
\hline
\end{tabular}


In this sense, three relationships between design elements have proved to be fundamental for initiatives to succeed:

- Crowd sociocultural and economic context and task

- $\quad$ Space-temporal features of the initiative and crowd motivation

- Nature of the task and crowd motivation

About the first relationship, it is necessary to go beyond a task-centred design, considering the context in which the initiative will be carried out and its influence on the crowd. Nature of the crowd must be understood and considered (Hui, 2015), but also socioeconomic, cultural, and demographic factors.

It's important to know the positive, negative, or neuter influence of crowd culture and believes on the initiative. Obviously, this is only possible when trying to reach a crowd from a certain location, but not when trying to reach an heterogenous and wide crowd from everywhere. For example, doxing as crowdsourced task is acceptable in some countries (Chang \& Leung, 2015), but not in others.

Also crowd age and educational level are also important variables to be considered. For example, in urban areas, the elderly has greater access to the Internet, which could foster their participation in crowdsourcing initiatives. However, in rural areas, the same demographic has been shown to be more unwilling to learn how to use new technologies (Matveeva, 2013). Age and educational level, therefore, are crucial factors when it comes to the potential positive impact that technology could have on a project. Which technology is the most appropriate to use and how technologies should be combined are also important aspects to take into account (Mancini, 2013). So is not about using the most modern technology, but the one that best suits the context where the initiative is being developed (Mancini and O’Reilly, 2013).

For example, in an early warning system deployed in southern Kyrgyzstan, SMS was the best way the crowd could communicate because the initiative was focused on elderly women of low socioeconomical level (Matveeva, 2013). But in 'The Shoreditch Digital Bridge' case (Trottier, 2013), the most suitable ITC was CCTV due the population to which was focused (neighbours from London).

The second relationship between variables to highlight, is the one between the initiative spacetemporal characteristics and crowd motivation. For a crowdsourcing initiative to success, it is necessary to keep the crowd sufficiently motivated, a variable that is easier to achieve over a short time period as 
seen in successful initiatives like both Boston Marathon initiatives (Markowsky, 2013) or \#shopalooter (Denef et al., 2013). However, timings can also be influenced by the nature of the event or the task involved. Furthermore, a crime or a specific incident can provoke emotions that make the crowd more willing to participate. Space is also an important factor in two senses. In one side, tasks to be carried out in a limited geographical area, implies that the crowd to participate is easier to identify (stablishing contact and achieving participation is more complicated). It means that the initiative uses communities of place to carry out the task. In other side, as more located, easier is to reach the stablished goal of the initiative. For example, in EU Most Wanted Interpol initiative (BBC, 2017), Europol asks the crowd to look for a small set of persons in a wide geographical area, what is a difficult task. Not because the nature of the task, but for the wide range of area to cover. In exchange, UK Riots crowdsourcing initiative described by Denef et al. (2013) was a success, in part, because it implied communities of place of a really located area.

The third relationship to highlight is the one between the nature and objective of the initiative and crowd motivation. It is vital for the objective of the initiative to be specific and concise. These two characteristics allows the crowd to know exactly what they asked to do, what affects motivation of the crowd, and so their participation (or otherwise) in the project. But also, initiative's objective must be perceived to have meaningfulness and fairness (Chandler and Kapelner, 2013).

This meaningfulness and fairness favour intrinsic motivation, which is the most efective type of motivation. For this reason, in this type of initiatives, tangible reward can be counter-productive owing to the crowd-out effect (Dunphy et al., 2015). This effect implies a reduction in intrinsic motivation, and so in participation, when trying to increase extrinsic motivation using rewards.

This also happens in other crowdsourcing initiatives, such as citizen journalism, where the most noteworthy source of motivation is the impact that it will have on the common good (Aitamurto, 2015).

\section{Conclusions}

When it comes to security issues in modern societies, it is important to get citizens involved. However, their mere participation alone may not always be enough (Mancini and O’Reilly, 2013). Likewise, new technologies can be very useful to avoid conflicts in specific situations. But again, they are not a panacea for holistic solutions, and ICTs alone will not resolve the problems of crime and corruption (Mancini and O'Reilly, 2013). ICT is solely a tool for, not the driver of, reform. It is a means, not an end (Livingston, 
2013; Matveeva, 2013).

However, cooperation between professional security agencies and citizens through technology can make a significant difference when it comes to tackling crime and, in consequence, it must not be underestimated (Hui, 2015). Thus, the possibility exists to use crowdsourcing through technology in order to support formal social control. Citizens, in different types of communities, can act not only as 'the eyes and ears' of the state security forces, but they can also become close cooperators who carry out specific tasks.

As has been explained in this study, not all tasks can be done through crowdsourcing because time-space factors exist that determine the success (or failure) of these initiatives. There are also some contingent structural conditions, such as the relative loss of control, that must be accepted if law enforcement agencies want citizens to become participants. Obviously, this factor is not always acceptable to the crowdsourcer. Furthermore, crowdsourcing tasks must be considered useful, meaningful, and valuable by the citizens who are involved. Finally, it must not be forgotten that the objective of these tandem "public safety - ITC - citizen" initiatives should be to create an effective public safety system that improves the lives of citizens (Perlman, 2012).

This research has its own limitations. Although general conclusions about the design elements of these initiatives have been exposed, each one will strongly depend on the sociocultural features of the crowd who is going to carry out the different tasks. So those factors and characteristics always should be analysed from the participant crowd perspective. A second limitation is the set of initiatives analysed. There are other crowdsourcing initiatives used for formal social control that not have been published in academic documents or in the news sources selected.

Regarding future research lines, an in-depth study of CI in specific contexts could be carried out. For example, given its relevance in today's world, it would be interesting to analyze how formal and informal social control could be applied in cyber-security related tasks. In addition, the type of tasks (such as, malware analysis, OSINT tasks, etc.) could also be considered in the study, as well as different types of organizations (including groups of volunteers, cyber reserves, etc.). In both cases, an analysis of the tasks carried out and the types of organizations involved would need to be done. In addition, new CI task types could also be suggested with the help of qualified experts. It would also be worth establishing specific criteria to identify those situations in which CI through formal social control could be applied as a preference and those which CI through informal social control would be more recommendable. 


\section{References}

<Author1>

$<$ Author2>

Aitamurto, T. (2015). Motivation factors in crowdsourced journalism: Social impact, social change, and peer learning. International Journal of Communication, 9(1), 3523-3543.

Andrews S. (2017) Best Practices in the Design of a Citizen Focused Crisis Management Platform. In Akhgar B., Staniforth A., Waddington D. (eds) Application of Social Media in Crisis Management (pp. 59-79), Springer. https://doi.org/10.1007/978-3-319-52419-1_5

Ariffin, I., Hanif, M.F.M., \& Solemon, B. (2015). UniCrime: A mobile solution for on campus crime reporting using volunteered geographic information. In Ma M. (Ed), Proceedings of the 5th International Workshop on Computer Science and Engineering: Information Processing and Control Engineering (pp. 792-797). https://doi.org/10.18178/wcse.2015.04.126

Avvenuti, M., Cresci, S., Vigna, F.D., \& Tesconi, M. (2018). On the need of opening up crowdsourced emergency management systems. AI and Society, 33(1), 55-60. https://doi.org/10.1007/s00146017-0709-4

BBC. (2017, June 1st). Europol shows clues from child abuse images to track offenders. BBC News. https://www.bbc.com/news/world-europe-40115549

Bigham, J.P., Bernstein, M.S., \& Adar, E. (2015). Human-computer interaction and collective intelligence. In Malone, W., Bernstein, M.S. (eds.) Handbook of Collective Intelligence. MIT Press.

Brabham, D. (2013). Using Crowdsourcing in Government. IBM Center for Business of Government. https://bit.ly/3bJTBE0

Brito, P.L., Jesus, E.G.V., Sant' Ana, R.M.S., Martins, C., Delgado, J.P.M., \& Fernandes, V.O. (2014). Official crime data versus collaborative crime mapping at a Brazilian city. In Proceedings of the International Archives of Photogrammetry, Remote Sensing and Spatial Information Sciences, 40(2), 137-138. https://doi.org/10.5194/isprsarchives-XL-2-137-2014

Castillo, A.M.C. (2020). El Derecho Humano de Protección de Denunciantes de Corrupción a través de la Política Pública en México (2013-2019). Revista española de la transparencia, (11), 157-187. https://doi.org/10.51915/ret.113

Chand, D.M., Sankaranarayanan, S., \& Sharma, C. (2014). Project Jagriti: Crowdsourced Child Abuse Reporting. In Proceedings of the Fourth IEEE Global Humanitarian Technology Conference (pp. 609-613). https://doi.org/10.1109/GHTC.2014.6970346

Chandler, D., \& Kapelner, A. (2013). Breaking monotony with meaning: Motivation in crowdsourcing markets. Journal of Economic Behavior \& Organization, 90, 123-133. https://doi.org/10.1016/j.jebo.2013.03.003

Chandrasekaran, V., Rajan, S.V., Vasani, R.K., Menon, A., Bagavathi Sivakumar, P., \& Shunmuga Velayutham, C. (2016). A Crowdsourcing-Based Platform for Better Governance. In Suresh L., Panigrahi, B. (eds) Proceedings of the International Conference on Soft Computing Systems (pp. 519-527). https://doi.org/10.1007/978-81-322-2671-0_50 
Chang, L.Y.C., Leung, A.K.H. (2015). An Introduction to Cyber Crowdsourcing (Human Flesh Search) in the Greater China Region. In Smith R. G., Cheung R. CC., Lau L. YC. (eds) Cybercrime Risks and Responses (pp. 240-252). Palgrave Macmillan. https://doi.org/10.1057/9781137474162_16

Cohen, L.E, \& Felson, M. (1979) On estimating the social costs of national economic policy: A critical examination of the Brenner study. Social Indicators Research, 6(2), 251-259. https://doi.org/10.1007/BF00343977

Cordis (n.d.) Athena. https://cordis.europa.eu/project/id/313220/es

Denef, S., Bayerl, P.S., \& Kaptein, N.A. (2013). Social media and the police: tweeting practices of british police forces during the August 2011 riots. In Proceedings of the SIGCHI Conference on Human Factors in Computing Systems (pp. 3471-3480). ACM. https://doi.org/10.1145/2470654.2466477

Denyer, D. \& Tranfield, D. (2008). Producing a systematic review. In Buchanan, D. (ed.), The Sage Handbook of Organizational Research Methods. London: Sage.

Domdouzis, K., Akhgar, B., Andrews, S., Gibson, H. \& Hirsch, L. (2016). A social media and crowdsourcing data mining system for crime prevention during and post-crisis situations. Journal of Systems and Information Technology, 18 (4), 364-382. https://doi.org/10.1108/JSIT06-2016-0039

Dunphy, P., Nicholson, J., Vlachokyriakos, V., Briggs, P., \& Olivier, P. (2015). Crowdsourcing and CCTV: the effect of interface, financial bonus and video type. (Report $\left.\mathrm{n}^{\circ} \mathrm{CS}-\mathrm{TR}-1453\right)$. Newcastle University. https://assets.cs.ncl.ac.uk/TRs/1453.pdf

El Abdallaoui, H.E.A., El Fazziki, A., Sadiq, A., Zohra, E.F., \& Sadgal, M. (2016). A web based crowdsourcing framework: Lost child case. In $4^{\text {th }}$ IEEE International Colloquium on Information Science and Technology (pp. 263-268). IEEE. https://doi.org/10.1109/CIST.2016.7805053

Estellés-Arolas, E., \& González-Ladrón-De-Guevara, F. (2012). Towards an integrated crowdsourcing definition. Journal of Information science,38(2), 189-200. https://doi.org/10.1177\%2F0165551512437638

FBI (2014, octubre 7). Seeking Information. Help Identify Individuals Traveling Overseas for Combat. https://www.fbi.gov/news/stories/help-identify-individuals-traveling-overseas-for-combat/helpidentify-individuals-traveling-overseas-for-combat

Hamilton, M., Salim, F., Cheng, E., \& Choy, S.L. (2011). Transafe: a crowdsourced mobile platform for crime and safety perception management. In 2011 IEEE International Symposium on Technology and Society (ISTAS) (pp. 1-6). https://doi.org/10.1109/ISTAS.2011.7160600

Huey, L., Nhan, J., \& Broll, R. (2013). 'Uppity civilians' and 'cyber-vigilantes': The role of the general public in policing cyber-crime. Criminology \& Criminal Justice, 13(1), 81-97. https://doi.org/10.1177/1748895812448086

Hui, J. Y. (2015). Crowdsourcing for national security. S. Rajaratnam School of International Studies. http://www.jstor.org/stable/resrep05853

Kelly, H. (2014, May 16). Hyperlocal apps help residents fight crime. CNN Business. http://edition.cnn.com/2014/05/14/tech/social-media/neighborhood-watchappsnextdoor/index.html 
Khanwalkar, S.S. (2016). Crime intelligence 2.0: reinforcing crowdsourcing using artificial intelligence and mobile computing [Doctoral dissertation, University of California, Irvine] Semantic Scholar. https://escholarship.org/uc/item/6965r2v6

Knox, C.C. (2016). Public Administrators' Use of Social Media Platforms: Overcoming the Legitimacy Dilemma?. Administration \& Society, 48(4), 477-496. https://doi.org/10.1177/0095399713503463

Lally, N. (2017). Crowdsourced surveillance and networked data. Security Dialogue, 48(1), 63-77. https://doi.org/10.1177/0967010616664459

Larrauri, H.P. (2013). New technologies and conflict prevention in Sudan and South Sudan. In F. Mancini (Ed.), New technology and the prevention of violence and conflict (pp. 71-86). International Peace Institut.

Liu, H.K. (2017). Crowdsourcing Government: Lessons from Multiple Disciplines. Public Administration Review, 77(5), 656-667. https://doi.org/10.1111/puar.12808

Malone, T.W. (2018). Superminds: The surprising power of people and computers thinking together. Little, Brown Spark.

Malone, T.W., \& Bernstein, M.S. (Eds.). (2015). Handbook of collective intelligence. MIT Press.

Mancini, F. \& O'Reilly, M. (2013). New technology and the prevention of violence and conflict. Stability: International Journal of Security \& Development, 2(3), 55. https://doi.org/10.5334/sta.cp

Mancini, F. (2013). New technology and the prevention of violence and conflict. International Peace Institute.

Markowsky, G. (2013). Crowdsourcing, big data and homeland security. In 2013 IEEE International Conference on Technologies for Homeland Security (HST) (pp. 772-778). IEEE. https://doi.org/10.1109/THS.2013.6699101

Matveeva, A. (2013). Conflict cure or curse? Information and communication technologies in Kyrgyzstan. In F. Mancini (Ed.), New technology and the prevention of violence and conflict (pp. 56-70). International Peace Institut

McHugh, K. (2011, september 30). My Virtual Neighbor is a Social Network for Your Street. Adweek. http://www.adweek.com/digital/my-virtual-neighbor-is-a-social-network-for-your-street/

Ministry of Interior. (n.d.). Alertcorps. La app de la Policía y la Guardia Civil. https://alertcops.ses.mir.es/mialertcops/

Muggah, R., \& Diniz, G. (2013). Using Information and Communication Technologies for Violence Prevention in Latin America. In F. Mancini (Ed.), New technology and the prevention of violence and conflict (pp. 28-14). International Peace Institut.

Musila, G.M. (2013). Early warning and the role of new technologies in Kenya. In F. Mancini (Ed.), New technology and the prevention of violence and conflict (pp. 42-55). International Peace Institut.

Nahn, J., Huey, L., \& Broll, R. (2017). Digilantism: An Analysis of Crowdsourcing and the Boston Marathon Bombings. British Journal of Criminology, 57(2), 341-361. https://doi.org/10.1093/bjc/azv118 
Nam, T. (2012). Suggesting Frameworks of Citizen-Sourcing via Government 2.0 . Government Information Quarterly, 29(1), 12-20. https://doi.org/10.1016/j.giq.2011.07.005

Perlman, M. (2012). Using Technology to Enhance Communities' Engagement with Public Safety.

National League of Cities, Center for Research \& Innovation.

Redondo, S., \& Garrido, V. (2013). Principios de criminología. Tirant lo Blanc

Rescher, N. (1999). Razón y valores en la era científico-tecnológica. Paidós.

See, L., Mooney, P., Foody, G., Bastin, L., Comber, A., Estima, J., ... Rutzinger, M. (2016).

Crowdsourcing, citizen science or volunteered geographic information? The current state of crowdsourced geographic information. ISPRS International Journal of Geo-Information, 5(5), 55. https://doi.org/10.3390/ijgi5050055

Shah, S., Bao, F., Lu, C.T., \& Chen, I.R. (2011). Crowdsafe: crowd sourcing of crime incidents and safe routing on mobile devices. In Proceedings of the 19th ACM SIGSPATIAL International Conference on Advances in Geographic Information Systems (pp. 521-524). ACM. https://doi.org/10.1145/2093973.2094064

Shiffman, G.M., \& Gupta, R. (2013). Crowdsourcing cyber security: a property rights view of exclusion and theft on the information commons. International Journal of the Commons, 7(1), 92-112. https://doi.org/10.18352/ijc.343

Sloane, P. (2011). A Guide to Open Innovation and Crowdsourcing: Advice from Leading Experts in the Field. Kogan Page Publishers.

Tonkin, E., Pfeiffer, H.D., \& Tourte, G. (2012). Twitter, information sharing and the London riots?. Bulletin of the American Society for Information Science and Technology, 38(2), 49-57. https://doi.org/10.1002/bult.2012.1720380212

Trottier, D. (2014). Crowdsourcing CCTV surveillance on the Internet. Information Communication \& Society, 17(5), 609-626. https://doi.org/10.1080/1369118X.2013.808359

Xiao, Y., \& Watson, M. (2019). Guidance on conducting a systematic literature review. Journal of Planning Education and Research, 39(1), 93-112. https://doi.org/10.1177\%2F0739456X17723971

Yayla, A.S., \& Speckhard, A. (2017). Telegram: The mighty application that ISIS loves. International Center for the Study of Violent Extremism. http://www.icsve.org/brief-reports/telegram-themighty-application-that-isis-loves/

Zeteky (n.d.) Torch App. https://web.archive.org/web/20181206144032/https://www.torch.tips/ 